\title{
CONGENITAL HEART DISEASE
}

\section{Use of the Amplatzer muscular ventricular septal defect occluder for closure of perimembranous ventricular septal defects}

\author{
M Szkutnik, S A Qureshi, J Kusa, E Rosenthal, J Bialkowski
}

Heart 2007;93:355-358. doi: 10.1136/hrt.2006.096321

See end of article for authors' affiliations

.....................

Correspondence to: J Bialkowski, Department of Congenital Heart Disease and Pediatric Cardiology, Silesian Center for Heart Disease, 41800 Zabrze, ul. Szpitalna 2, Poland; jabi_med@poczta.onet.pl

Accepted 9 August 2006 Published Online First 15 September 2006 .....................
Background: Transcatheter closure of a perimembranous ventricular septal defect (PmVSD) is usually performed with an asymmetric Amplatzer occluder, which is not an ideal device. Experience with the use of the Amplatzer muscular ventricular septal defect occluder (MVSO) to close selected PmVSDs is presented. Setting: Two tertiary referral centres for paediatric cardiology in two countries.

Objective: To look at the safety and efficacy of the application of the MVSO in patients with appropriate PmVSD anatomy.

Patients and intervention: The procedure was performed in 10 patients aged 3.2-40 (mean 12.5) years. All had a PmVSD with a mean diameter of 5.4 (range 4-11) mm, with an extension towards the muscular septum. The mean distance of the defect from the aortic valve was 5.4 (range 4-6) $\mathrm{mm}$. In all but one patient, the MVSO was introduced in routine antegrade transvenous fashion (4-mm device in one patient, 6-mm device in five, $8 \mathrm{~mm}$ in two, $10 \mathrm{~mm}$ in one, and $12 \mathrm{~mm}$ in one). In one patient, the device was deployed by retrograde implantation.

Results: All procedures except one were performed without complications, and complete closure of the VSD was achieved. One patient with a residual shunt developed haemolysis, which resolved over 10 days. In three patients, trivial, non-progressive tricuspid regurgitation appeared after the procedure. No other complications were observed over 1.7 (range 0.2-3.5) years of follow-up.

Conclusion: Application of the MVSO for closure of selected PmVSDs seems to be a safe and effective treatment option.
$\mathrm{V}$ entricular septal defects (VSDs) are the most common form of congenital cardiac malformation, comprising $20 \%$ of all congenital heart disease; $80 \%$ of these defects are perimembranous, involving the membranous septum and usually the adjacent muscular septum. Therefore these defects are commonly termed perimembranous VSDs (PmVSDs). Their surgical closure is safe with a very low mortality. However, residual shunts, tricuspid incompetence, complete heart block, early and late arrhythmias, and post-pericardiotomy syndrome may occur on occasions. Complications of cardiopulmonary bypass and blood priming are well documented, and surgery, although safe, has a degree of morbidity, discomfort for the patient, and a thoracotomy scar. Therefore an alternativetranscatheter closure of the PmVSD-has been attempted with various types of occluding devices. The ideal device has not been invented as yet, and the special asymmetric Amplatzer occluder designed for such purposes is not perfect. The close proximity to the conduction system and the aortic and/or atrioventricular valve apparatus of PmVSD could produce potential complications, such as rhythm disturbances or valve incompetence. In this article, we have compared the occurrence of rhythm disturbances in patients in whom PmVSDs were closed interventionally with an eccentric Amplatzer occluder and the Amplatzer muscular ventricular septal defect occluder (MVSO). However, the main purpose of this study is to report the results of transcatheter closure of PmVSDs in specially selected patients using the MVSO.

\section{METHODS}

Patients

The procedure was performed in 10 patients, aged 3.2-40 (mean 12.5, median 8.65) years with mean body weight 31 (median 25.5; range $14-56) \mathrm{kg}$. They were selected by transthoracic echocardiography based on the distance between the PmVSD and the aortic valve (aortic rim) being $\geqslant 4 \mathrm{~mm}$, with a significant left-to-right shunt, and with documented left ventricular volume overload. All defects were perimembranous inlet or outlet and extended into the muscular part of the septum. In three patients, aneurysm of the interventricular septum was diagnosed by echocardiography and later confirmed by angiography (fig 1A). One of these had two defects. Table 1 shows the clinical and haemodynamic data. We also treated interventionally 14 patients with PmVSD in whom asymmetric Amplatzer devices were used. The mean age of these patients was 13 (5-38) years, body weight 47.5 (19101) $\mathrm{kg}$, VSD diameter $6(4-12) \mathrm{mm}$, and aortic rim 5 (28) $\mathrm{mm}$.

\section{Device}

The MVSO (AGA Medical Corporation, Golden Valley, Minnesota, USA) was designed specifically for closure of VSDs located in the muscular septum. The double-disc nitinol plug has a 7-mm long connecting waist; the left retention skirt is $4 \mathrm{~mm}$ larger than the waist diameter, and the right retention skirt is $3 \mathrm{~mm}$ larger. The MVSO is available in sizes ranging from 4 to $18 \mathrm{~mm}$, in 2 -mm waist diameter increments. The device is passed through a standard AGA delivery system and is attached to a delivery cable by a recessed screw.

Abbreviations: MVSO, Amplatzer muscular ventricular septal defect occluder; PmVSD, perimembranous ventricular septal defect; TEE, transoesophageal echocardiographic 

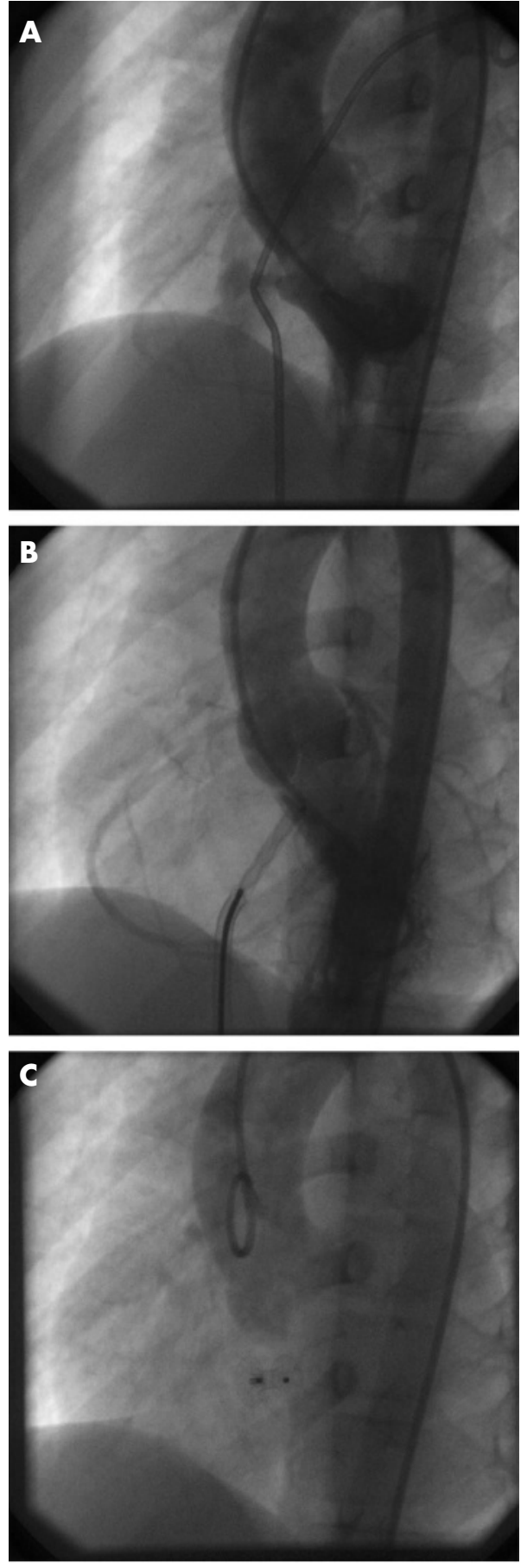

Figure 1 Transcatheter closure of perimembranous ventricular septal defect (PmVSD) with an Amplatzer Muscular Septal Occluder (MVSO) (long axial oblique view). (A) Diagnostic left ventriculogram; left-to-right shunt through 5-mm PmVSD with 5-mm aortic rim (formed by the muscular part of the interventricular septum). (B) The distal disc of the MVSO opened in the mouth of the defect; the rest of the device still inside the trans-septal sheath still connected to the delivery cable. (C) Control aortography after release of the device showing no aortic regurgitation.

\section{Techniques}

All the procedures were performed under transoesophageal echocardiographic (TEE) and fluoroscopic monitoring similar to the technique previously described. ${ }^{12}$ Standard right and left heart catheterisation was performed, and a left ventricular angiogram was obtained in the long axial oblique view (fig lA). The defect was measured at the end of diastole in the view that showed the best profile of the defect. The VSD was crossed in a retrograde fashion using a $5 \mathrm{~F}$ or $6 \mathrm{~F}$ right coronary Judkins catheter (Cordis Corporation, Miami, Florida, USA) and hydrophilic guide wire. After crossing the defect, the hydrophilic wire was replaced by a soft J-tipped $260-\mathrm{cm}$ exchange 0.035 -inch guide wire, which was advanced into the pulmonary artery, where it was snared using a $10-15-\mathrm{mm}$ gooseneck snare (Microvena Corporation, White Bear Lake, Minnesota, USA) and exteriorised through the right femoral vein, creating a stable arteriovenous loop. The retrograde catheter was advanced across the VSD over the exchange wire with its end left in the junction of the inferior vena cava and the right atrium. A trans-septal sheath 6-8 F with 180 degree of distal curve (AGA Medical Corporation) together with a dilator were advanced over the wire from the femoral vein until the tip of the dilator touched the tip of the retrograde catheter (the "kissing catheter" technique). The long sheath was advanced through the VSD to the ascending aorta by pushing the sheath and pulling the arterial catheter. Once the sheath had crossed into the aorta, the wire and the arterial catheter were withdrawn from the arterial side, and a pigtail catheter was introduced into the left ventricle. The dilator was removed from the sheath, and the sheath was flushed with saline. An appropriate sized MVSO was screwed to the tip of the delivery cable, collapsed into a loader, and advanced to the tip of the sheath in the ascending aorta. The MVSO was selected to be equal to or 1-2 mm larger than the PmVSD diameter, estimated by echocardiography and angiography during diastole. The left ventricular disc was partially deployed in the ascending aorta, assuming a "bubble shape". The whole system was then gently pulled until the device "dropped" through the aortic valve into the left ventricle outflow tract. In this position, the rest of the left ventricular disc was opened and the whole system was withdrawn under TEE monitoring to the mouth of the defect. At this point, a left ventriculogram was performed to assess the position of the device (fig 1B). The right ventricular disc was deployed by gently pulling the sheath over the delivery cable. TEE was then repeated before and after release of the device. In three of our cases in the presence of "aneurysmatic" PmVSD, the MVSO was implanted to stent the left ventricular entrance of the aneurysm. The connecting waist of the device in such circumstances adapted nicely to the depth of the aneurysm. Control aortography after release was performed to exclude aortic regurgitation (fig $1 \mathrm{C}$ ). In one patient (table 1 , number 7 ) with a 4-mm aortic rim, it was thought that the retrograde arterial method of implantation would be best, as the proximal disc of the device is $1 \mathrm{~mm}$ smaller $(3 \mathrm{~mm}$ ) than the distal one $(4 \mathrm{~mm})$. In this patient, a Judkins right coronary catheter was placed through the defect in the apex of the right ventricle and over an exchange guide wire replaced by a $7 \mathrm{~F}$ and $180^{\circ}$ curved trans-septal sheath (without an arteriovenous loop creation). The distal disc of the MVSO was opened in the body of the right ventricle, and the whole system was pulled under TEE guidance to the entrance of the aneurysm of the interventricular septum, and the proximal disc was opened. At the beginning, the proximal disc had a "bubble shape" and failed to conform properly. By repeated pulling on the delivery cable with gentle pushing forward of the sheath against the disc, we finally succeeded in correctly conforming the device in the mouth of the aneurysm. Repeat TEE and angiography were performed through the side arm of the delivery sheath before and then after release of the device to assess the final device position and the presence of a residual shunt. The devices used included a 4$\mathrm{mm}$ MVSO in one patient, a 6-mm device in five, $8 \mathrm{~mm}$ in two, $10 \mathrm{~mm}$ in one, and $12 \mathrm{~mm}$ in one. All the patients, except one 
Table 1 Clinical and haemodynamic data in 10 patients with perimembranous ventricular septal defect

\begin{tabular}{|c|c|c|c|c|c|c|c|c|c|}
\hline Patient & $\begin{array}{l}\text { Age } \\
\text { (years) }\end{array}$ & $\begin{array}{l}\text { Weight } \\
(\mathrm{kg})\end{array}$ & QP/QS & $\begin{array}{l}\text { VSD } \\
(\mathrm{mm})\end{array}$ & $\begin{array}{l}\text { Aortic } \\
\text { rim } \\
(\mathrm{mm})\end{array}$ & $\begin{array}{c}\text { MVSO } \\
(\mathrm{mm})\end{array}$ & $\begin{array}{l}\text { Fluoroscopy } \\
\text { time (min) }\end{array}$ & $\begin{array}{l}\text { Procedure } \\
\text { time (h) }\end{array}$ & $\begin{array}{l}\text { Follow-up } \\
\text { (years) }\end{array}$ \\
\hline 1 & 9.3 & 30 & 1.7 & 4 & 5 & 6 & 23 & 1.2 & 3.5 \\
\hline 2 & 11 & 29 & 1.8 & 4 & 6 & 6 & 29 & 2.0 & 3.4 \\
\hline 3 & 3.2 & 14 & 1.6 & 4 & 5 & 6 & 22 & 1.5 & 2.8 \\
\hline 4 & 8 & 22 & 1.6 & 4.5 & 6 & 6 & 49 & 2.2 & 2.6 \\
\hline 5 & 20 & 48 & 1.6 & 5 & 6 & 8 & 17 & 1.2 & 2.4 \\
\hline 6 & 4.7 & 20 & 6.0 & 9 & 6 & 10 & 12 & 2.0 & 1.0 \\
\hline 7 & 7 & 19 & 1.8 & $4.5,3.5^{*}$ & 4 & 8 & 19 & 1.5 & 0.8 \\
\hline 8 & 40 & 56 & 2.0 & 5.5 & 6 & 6 & 19 & 1.2 & 0.3 \\
\hline 9 & 13.5 & 31 & 2.0 & 11 & 5 & 12 & 16 & 1.25 & 0.2 \\
\hline 10 & 8.0 & 19 & 1.6 & 4 & 4,5 & 4 & 16 & 2.0 & 0.2 \\
\hline Mean & 12.5 & 28.8 & 2.2 & 5.6 & 5.4 & & 22 & 1.6 & 1.7 \\
\hline
\end{tabular}

MVSO, Amplatzer Muscular Ventricular Septal Defect Occluder; VSD, ventricular septal defect.

*Two defects inside the anurysm of interventricular septum.

with haemolysis observed after implantation, were discharged after 2 days on aspirin for 6 months and advised to use bacterial endocarditis prophylaxis for 6 months. They were reassessed after 1 month, 6 months and once a year thereafter. The fluoroscopy time ranged from 12 to 49 min (mean 22.2, median 19.0).

\section{RESULTS}

The procedure was technically successful in all patients, with complete closure of the defect after 24 hours confirmed by transthoracic echocardiography in all but one. One patient with a residual shunt (patient number 6 in table 1) developed moderately severe haemolysis, which resolved spontaneously over 10 days with conservative management. None of the patients had aortic or mitral regurgitation, but tricuspid regurgitation was diagnosed in three (trivial in two and mild in one); this did not progress in severity during follow-up. The only case of mild tricuspid regurgitation was the one in which retrograde implantation of the device was performed and the distal disc was opened in the right ventricle. The likely explanation for the tricuspid regurgitation was some restriction of movement of the tricuspid valve by the right sided disc of the device. In one patient (number 7), transient loss of the femoral pulse occurred and was treated successfully with heparin infusion for $24 \mathrm{~h}$. No other complications, including atrioventricular heart blocks, occurred during 0.2-3.5 (mean 1.7) years of follow-up. In contrast, among the 14 patients in whom the PmVSD was closed with an eccentric device, there were five with major rhythm disturbances during or after the procedure. The more common occurrence of this complication in the asymmetric Amplatzer group compared with the MVSO group was close to significant ( $p=0.053$; Fisher's exact test). In the first patient treated with eccentric Amplatzer, the procedure was abandoned when the heart block appeared just after the sheath had been passed through the VSD and directed to the left apex. In the second patient, a rhythm disturbance (first degree atrioventricular block with left bundle branch block and periodically third degree atrioventricular block) appeared in the first week after implantation of the eccentric Amplatzer occluder and resolved after steroid treatment. In the third patient, a third degree atrioventricular block manifested itself immediately after implantation and disappeared after removal of the device. In two other patients, a heart block appeared in the later follow-up (after discharge). In these patients, a permanent pacemaker was implanted after steroid treatment had failed.

\section{DISCUSSION}

Attempts at transcatheter PmVSD closure are not new. They have been performed with several occluding devices such as the
Rashkind double umbrella, ${ }^{3-6}$ coils $^{56}$ and the Button device. ${ }^{7}$ None of these devices were specifically designed for closure of PmVSDs and none gained wide acceptance, because of technical limitations, significant rate of residual shunts, and complications. A new era of percutaneous treatment appeared with the introduction of specially designed Amplatzer devices. In 1999, the first cases of transcatheter closure of muscular VSDs with an MVSO were reported, ${ }^{18}$ and since then transcatheter closure of PmVSDs with specially designed eccentric Amplatzer devices has also been reported. ${ }^{9-14}$ The results with these new devices are well documented in the literature. ${ }^{18-14}$ There are two reasons why we used a muscular device instead of a perimembranous one. At the beginning (in the first two cases), there was only one device available; later it was our choice (after an unfavourable experience with an asymmetric device and conduction problems). Percutaneous closure of the PmVSD remains the biggest challenge for the cardiologist, because of its close proximity to the aortic and tricuspid valves as well as the conduction system, which passes at the posterior border of these defects. The Amplatzer perimembranous ventricular septal defect occluder has a very short connecting waist $(1.5 \mathrm{~mm})$ and asymmetric left ventricular disc designed to avoid impingement on the aortic valve. This is accomplished by a comparatively complicated introduction system, which has been described previously. ${ }^{12-14}$ Owing to the eccentric design of the left ventricular disc, correct orientation of the device has to be achieved for successful deployment. However, a major concern remains, namely the occurrence of complete heart block, which has been reported with the use of the eccentric Amplatzer device by different centres. $^{9}{ }^{14}{ }^{15}$ Although the frequency of the latter complication is reported to be around 3.5\% (comparable to surgical results), it is still of concern. ${ }^{15}$ This complication also occurred in five of our 14 patients treated with this device and in none treated with the MVSO $(p=0.053)$. It is not known whether complete heart block after use of the asymmetric device is caused by the trauma of the catheterisation with local haematoma formation, an inflammatory response to the device, compression of the interventricular septum between two discs, or the continued mechanical expansion of the nitinol device exerting pressure on the conducting system. These complications may also be explained in part by the fact that sizing of the defects is extremely vague because balloon sizing is not feasible. Consequently, oversized devices are commonly introduced which exert excessive pressure on the bundle of His. Our study, although it includes only a small number of patients, has shown that, in selected cases of PmVSD with a distance of the defect to the aortic valve $\geqslant 4 \mathrm{~mm}$ (length of the left retention skirt of the device is $4 \mathrm{~mm}$ ), a MVSO can be successfully 
implanted without creation of aortic regurgitation or rhythm disturbances. It is possible that there is less compression of the device on the bundle of His because of increased separation between the two discs of the device, but it has not been experimentally proved. We cannot exclude the possibility that our clinical observation (lack of atrioventricular block in the MVSO group) is related to the slightly different anatomy of the VSD in the specially selected patients. On the other hand, with the 7-mm connecting waist, the right ventricular disc of the MVSO may interfere with tricuspid valve motion. This occurred in three of our patients, causing clinically insignificant tricuspid regurgitation. We have also shown that application of the MVSO is safe and efficient in patients with "aneurysmatic" PmVSD, as it was in three of our cases. In patients with coexisting aneurysms of the interventricular septum, other devices, such as the PFM coil, ${ }^{16}$ the Amplatzer duct occluder, ${ }^{17}$ and the wireless Sideris patch, ${ }^{18}$ have been used, but experience with these devices is very limited.

\section{CONCLUSION}

We have shown that, in some carefully selected cases, the Amplatzer MVSO can be used with good results.

\section{Authors' affiliations}

M Szkutnik, J Kusa, J Bialkowski, Department of Congenital Heart Disease and Pediatric Cardiology, Silesian Medical School, Silesian Center for Heart Disease, Zabrze, Poland

S A Qureshi, E Rosenthal, Department of Paediatric Cardiology, Evelina Children's Hospital, Guy's \& St Thomas' Hospital Trust, London, UK

Competing interests: None.

\section{REFERENCES}

1 Tofeig M, Patel RG, Walsh K. Transcatheter closure of a mid-muscular ventricular septal defect with an Amplatzer VSD occluder device. Heart 1999:81:438-40.

2 Hijazi ZM, Hakim F, Al-Fadley F, et al. Transcatheter closure of single muscular ventricular septal defects using the Amplatzer muscular VSD occluder: initial results and technical considerations. Catheter Cardiovasc Interv 2000;49:167-72

3 Lock JE, Block PC, Mc Kay RG, et al. Transcatheter closure of ventricular septal defects. Circulation 1988;78:361-8.

4 Vogel M, Rigby ML, Shore D. Perforation of the aortic valve cusp: complication of ventricular septal defect closure with a modified Rashkind umbrella. Pediatr Cardiol 1996; 17:416-18.

5 Rigby ML, Redington AN. Primary transcatheter closure of perimembranous ventricular septal defect. Br Heart J 1994:72:368-71.

6 Kalra GS, Verma PK, Dhall A, et al. Transcatheter device closure of ventricular septal defects: immediate results and intermediate-term follow-up. Am Heart J 1999;138:339-44.

7 Sideris EB, Walsh KP, Haddad JL, et al. Occlusion of congenital ventricular septal defects by the buttoned device. Heart 1997;77:276-9.

8 Thanopoulos BD, Tsaousis GS, Konstadopoulou GN, et al. Transcatheter closure of muscular ventricular septal defects with the Amplatzer ventricular septal defect occluder: initial clinical application in children. J Am Coll Cardiol 1999:33:1395-9.

9 Aurora R, Trehan V, Kumar A, et al. Transcatheter closure of congenital ventricular septal defects. Experience with various devices. J Interv Cardiol 2003;16:83-91.

$10 \mathrm{Hijazi}$ ZM. Catheter closure of atrial septal and ventricular septal defects using the Amplatzer devices. Circulation 2003; 12:63-72.

11 Gu X, Han YM, Titus JL, et al. Transcatheter closure of membranous ventricular septal defects with a new nitinol prosthesis in a natural swine model. Catheter Cardiovasc Interv 2000;50:502-9.

12 Bass JL, Karla GS, Arora R, et al. Initial human experience with the Amplatzer perimembranous ventricular septal occluder device. Catheter Cardiovasc Interv 2003;58:238-45.

13 Thanopoulos BD, Tsaousis GS, Karanasios E, et al. Transcatheter closure of perimembranous ventricular septal defects with the Amplatzer asymmetric ventricular septal occluder: preliminary experience in children. Heart 2003;89:918-22.

14 Pedra CAC, Pedra SRF, Esteves CA, et al. Transcatheter closure of perimembranous ventricular septal defects. Expert Rev Cardiovasc Ther 2004;2:253-64.

15 Walsh MA, Bialkowski J, Szkutnik M, et al. Atrioventricular block following transcatheter closure of perimembranous ventricular septal defects. Heart 2006;92:1295-7.

16 Kotthoff S, Le TP, Debus V. Late coil displacement after interventional closure of a perimembranous ventricular septal defect: a case report. Catheter Cardiovasc Interv 2005:66:273-6.

17 Tan CA, Levi DS, Moore JW. Percutaneous closure of perimembranous ventricular septal defect associated with a ventricular septal aneurysm using the Amplatzer ductal occluder. Catheter Cardiovasc Interv 2005;66:427-31.

18 Sideris EB, Macuil B, Varvarenco V, et al. Transcatheter patch occlusion of perimembranous ventricular septal defects. Am J Cardiol 2005;95:1518-21.

\section{bmjupdates+}

bmiupdates+ is a unique and free alerting service, designed to keep you up to date with the medical literature that is truly important to your practice.

bmjupdates+ will alert you to important new research and will provide you with the best new evidence concerning important advances in health care, tailored to your medical interests and time demands.

Where does the information come from?

bmjupdates+ applies an expert critical appraisal filter to over 100 top medical journals A panel of over 2000 physicians find the few 'must read' studies for each area of clinical interest

Sign up to receive your tailored email alerts, searching access and more...

www.bmjupdates.com 